\title{
JUURNAL.RU
}

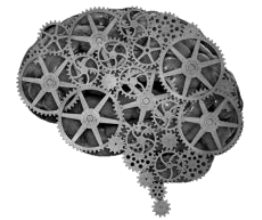

COMPANY GROUP "INTELLEKT"

\author{
Химичева Е.В. ${ }^{1}$, Сенченко Е.В. ${ }^{2}$, Полякова Н.В. ${ }^{3}$, \\ Недокушева О.Н. ${ }^{4}$, Яровая Р.С. ${ }^{5}$, Твердохлебова Е.В ${ }^{5}$. \\ ${ }^{1}$ МБУЗ городская больница № 11 \\ ${ }^{2}$ МБУЗ Детская поликлиника ГБ №1 \\ Ростов-на-Дону, Россия \\ ${ }^{3}$ МУЗ Детская больница \\ Белая Калитва, Россия \\ ${ }^{4}$ МУЗ ГП №1 \\ ${ }^{5}$ МУЗ городская больнииа скорой медииинской помощии \\ Волгодонск, Россия
}

doi: 10.18411/lj2016-7-2-15 idsp 000001: lj2016-16-2-15

\section{Эффективность препарата Синупрет в лечении острого риносинусита у детей}

Острый риносинусит (ОРС) является одним из наиболее распространенных заболеваний и доминирующим в структуре заболеваемости часто болеющих детей и детей с аденоидитами $[1,2]$. В большинстве случаев развитие ОРС связано с респираторной вирусной инфекцией. Эпителиотропные вирусы вызывают нарушение мукоцилиарного транспорта и развитие воспаления в собственной пластинке слизистой оболочки полости носа, что, в свою очередь, приводит к блокаде устьев околоносовых пазух, увеличению продукции слизи с измененными реологическими характеристиками, вторичному нарушению местного иммунитета. В этих условиях бактериальная суперинфекция переводит течение острого катарального риносинусита в острый гнойный риносинусит. Проведение патогенетической терапии, направленной на восстановление дренажа и вентиляции околоносовых пазух на ранних этапах 
заболевания может предотвратить развитие гнойного воспалительного процесса в околоносовых пазухах.

Целью нашего исследования было изучение эффективности использования препарата Синупрет, эффективность и безопасность которого при лечении взрослого контингента больных подтверждена рядом клинических исследований $[3,4,5]$, в терапии при ОРС у детей.

Синупрет является комбинированным препаратом растительного происхождения. Он содержит широкий спектр биологически активных веществ: корень генцианы - горечи; цветы первоцвета - сапонины и флавоноиды; трава щавеля - эмодин, щавелевую кислоту, флавоноиды; цветы бузины - стеролы, тритерпены, флавоноиды; трава вербены - биофенолы, вербеналин. Эти компоненты обладают противовоспалительным, секретолитическим, противовирусным и иммуномодулирующим действием. Входящие в его состав биофлавоноиды способны блокировать синтез основных медиаторов воспаления, а сапонины - стимулировать секреторные клетки слизистой оболочки полости носа, что снижает вязкость отделяемого и облегчает его эвакуацию. Учитывая роль провоспалительных цитокинов и иммунологических факторов в механизмах развития острого риносинусита $[6,7,8,9]$, Синупрет является средством патогенетической терапии воспалительных заболеваний носа и околоносовых пазух.

\section{Материал и методы исследования.}

Исследование проведено на базе 5 детских поликлиник Ростовской области. В исследование включено 127 детей в возрасте от 2 до 14 лет (средний возраст 6,3 лет) с давностью ОРС на фоне респираторно-вирусной инфекции не более 2 дней, не получавших в последние две недели лечения антибиотиками.

Для реализации поставленной цели были сформированы 2 группы: 1 основная группа (107 больных) и 2 - группа сравнения (20 больных). Основная группа была представлена двумя подгруппами: в группу 1а включено 42 ребенка в возрасте от 2 до 6 лет (средний возраст - 4,8 года), в 1 группу $16-65$ детей от 
7 до 14 лет (средний возраст - 8,1 лет). У 76 детей (60,3\%) было диагностировано легкое течение ОРС, у 51 (39,7\%) - заболевание протекало в среднетяжелой форме. Степень тяжести течения определяли на основании жалоб, анамнеза, данных осмотра и общеклинических методов исследования.

При первичном обращении всем больным назначали деконгестанты местного действия, носовой душ с физиологическим раствором, антигистаминные и противовирусные препараты. Помимо этого, детям основной группы в качестве муколитического препарата назначали Синупрет в возрастной дозировке: детям от 2 до 6 лет - по 15 капель 3 раза в сутки, от 6 до 14 лет - по 25 капель или по 1 драже 3 раза в сутки.

Во время первого визита родителям были выданы бланки дневников наблюдения, в которых следовало отмечать динамику основных симптомов заболевания: общего самочувствия, заложенности носа, выделений из носа, обоняния. Динамика заболевания оценивалась родителями по 4 качественным характеристикам: ухудшение, без изменения, улучшение, выздоровление.

Степень нарушения общего самочувствия и выраженность основных симптомов ОРС (заложенность носа, выделения из носа, нарушение обоняния) оценивали по 4-х балльной системе от 1 до 4 баллов.

При повторных осмотрах (на 4, 8 и, при необходимости, 12 день заболевания) выполняли ЛОР осмотр, анализировали данные дневников, которые ежедневно заполняли родители, оценивали клиническую картину заболевания, эффективность и безопасность Синупрета, определяли дальнейшую тактику ведения больных:

- при купировании симптомов ОРС (исчезновении выделений из носа, восстановлении носового дыхания и обоняния до преморбидного уровня, нормализации температуры тела) терапия считалась успешной, а исследование законченным;

- при появлении симптомов острого гнойного риносинусита (появлении головной боли, боли в проекции околоносовых пазух, 
односторонний характер гнойных выделений из носа) или ухудшении состояния назначали антибактериальную терапию.

\section{Результаты и их обсуждение.}

До начала лечения бальная оценка симптомов, используемых для оценки тяжести заболевания, была практически одинаковой в обеих группах больных (в среднем 11,6 и 11,8 соответственно). Все пациенты с острыми неосложненными синуситами легкой и средней степени тяжести получали одинаковую базовую терапию, которая была начата не позднее 3 дня заболевания. Больным основной группы дополнительно был назначен Синупрет в возрастных дозировках.

Первое сравнение динамики симптомов заболевания было проведено на 8 день от начала лечения. Интегральная оценка динамики симптомов заболевания (выздоровление, улучшение, без перемен, ухудшение), проводимая по опроснику, выявила различия результатов в трех сравниваемых группах (таблица 1).

Таблица 1

Оченка динамика симптомов заболевания на 8 день от начала лечения.

\begin{tabular}{|c|c|c|c|c|c|c|}
\hline & \multicolumn{2}{|c|}{$\begin{array}{c}\text { Группа 1a } \\
n=42\end{array}$} & \multicolumn{2}{|c|}{$\begin{array}{c}\text { Группа 1б } \\
\mathrm{n}=65\end{array}$} & \multicolumn{2}{|c|}{$\begin{array}{c}\text { Группа сравн. } \\
\text { n = } 20\end{array}$} \\
\hline & $\begin{array}{l}\text { абсол. } \\
\text { колич. }\end{array}$ & в \% & $\begin{array}{l}\text { абсол. } \\
\text { колич. }\end{array}$ & в \% & $\begin{array}{l}\text { абсол. } \\
\text { колич. }\end{array}$ & в \% \\
\hline Выздоровление & 7 & $16,6 \%$ & 14 & $21,5 \%$ & 3 & $15 \%$ \\
\hline Улучшение & 29 & $69,2 \%$ & 47 & $72,3 \%$ & 13 & $65 \%$ \\
\hline Без перемен & 6 & $14,2 \%$ & 4 & $6,2 \%$ & 4 & $20 \%$ \\
\hline
\end{tabular}

Как следует из таблицы 1, наиболее заметные различия выявляются по показателю отсутствия изменений выраженности симптомов: минимальное количество больных, у которых не выявлено положительной динамики, обнаружено в группе 16 (дети от 7 до 14 лет), максимальное - в группе сравнения. В группе 1а отсутствие заметного улучшения отмечено у 14,2\% больных, то есть, больше, чем в группе 1б, но этот показатель достоверно отличается от такового в группе сравнения $(14,2 \%$ и $20 \%$ соответственно, p < $0,05)$.

Сопоставимые результаты получены и при сравнении оценки симптомов: во время второго после начала лечения визита (8 день от начала лечения) 
средняя оценка симптомов в группе 1 а составила 6,2 , в группе $16-5,6$, в группе сравнения $-6,9$.

Средняя продолжительность заболевания у детей основной группы была несколько меньше, чем в группе сравнения: в $1 \mathrm{a}-8,7$ дней, в $16-8,1$ дней, в группе сравнения - 9,6 дней.

При дальнейшем наблюдении назначение антибактериальной терапии в связи с развитием острого бактериального риносинусита потребовалось двум детям $(4,8 \%)$ из группы 1а, одному больному $(1,5 \%)$ из группы 16 и одному $(5 \%)$ из группы сравнения.

Наше исследование подтверждает имеющиеся в литературе сообщения о клинической эффективности назначения препарата Синупрет в комплексной терапии ОРС $[3,4,5]$. Все больные получали одинаковую патогенетическую терапию, направленную на устранения отека слизистой оболочки полости носа и улучшение эвакуации содержимого околоносовых пазух: деконгестанты, антигистаминные препараты, носовой душ. Однако у детей основной группы, получавшей дополнительно Синупрет в качестве муколитического и мукокинетического средства, получен более значимый терапевтический эффект уже через 6 дней от начала лечения.

У детей, получавших Синупрет, реже наблюдалось развитие бактериального гнойного риносинусита. Поскольку в настоящее время установлено, что основными патогенетическими факторами присоединения острого бактериального риносинусита на фоне респираторно-вирусной инфекции являются отек слизистой оболочки в области остиомеатального комплекса и снижение мукоцилиарного клиренса в околоносовых пазухах [10, $11,12]$, следует полагать, что именно включение Синупрета в комплексное лечение обеспечило дополнительный терапевтический успех в основной группе по сравнению с группой сравнения. 


\section{Литература:}

1. Бойко Н.В., Колесников В.Н., Левченко Е.В. Статистика причин затруднения носового дыхания. Российская ринология. 2007. № 2. С. 24-25.

2. Бойко Н.В., Бачурина А.С. Аденотомия и аденотонзиллотомия у детей с затруднением носового дыхания. Рос. ринология 2015; Т 23. №1. С. 9-12.

3. Шахова Е.Г. Сравнительная эффективность комбинированной терапии антибиотиком и секретолитиком у пациентов с острым гнойным риносинуситом. Российская оториноларингология. 2010. № 2. С. 170-175.

4. Попович В.И., Кривопустов С.П., Бекетова Г.В. Острый вирусный риносинусит у детей: мультидисциплинарный взгляд на проблему. В фокусе внимания - фитотерапия с доказанной эффективностью. Педиатрия. Восточная Европа. 2016. Т 13. № 1. С. 78-86.

5. Melzer J., Sailer R., Schapowal A., Brignoli R. Systematic review of clinical data with BNO-101 (Sinupret) in the treatment of sinusitis. Forsch Komplementmed. 2006. № 13. Р. 78-87.

6. Стагниева И.В., Симбирцев А.С. Эффективность иммуномодулирую-щей терапии у больных риносинуситом. Медицинская иммунология. 2015. Т. 17. № 5. С. 423-430.

7. Стагниева И.В., Симбирцев А.С. Иммуномодулирующая терапия у больных риносинуситом с латентным течением. Медицинская иммунология. 2015. Т. 17. № S. С. 423.

8. Стагниева И.В., Гукасян Е.Л., Сагакянц А.Б. Нарушение нейроиммунной реактивности у больных риносинуситом. Российская ринология. 2015. Т. 23. № 1. C. 25-28.

9. Стагниева И.В., Симбирцев А.С. Определение роли субстанции Р и болевого симптома в диагностике иммунных нарушений при риносинусите. Иммунология 2015. Т. 36. № 5. С. 295-300.

10. Завалий М.А., Балабанцев А.Г., Поспелов С.В. Влияние антисептика мирамистин на скорость мукоцилиарного транспорта слизистой оболочки полости носа. Российская ринология. 2001. № 2. С. 161.

11. Завалий М.А. Экспериментальное исследование поверхностной активности мукоцилиарной системы околоносовых пазух. Журнал ушных, носовых и горловых болезней. 2005. №6. С. 18.

12. Завалий М.А. Сравнительная гистология и физиология мерцательного аппарата респираторного эпителия. Таврический медико-биологический вестник. 2014. Т. 17. № 2. С. 46-52. 